\title{
PENURUNAN GULA DARAH PADA PASIEN DIABETES MELITUS TIPE II MELALUI SENAM KAKI DIABETES
}

\author{
Bangun Dwi Hardika ${ }^{1}$ \\ ${ }^{1}$ Program Studi Ilmu Keperawatan, Fakultas IImu Kesehatan Universitas Katolik Musi Charitas, Sumatera Selatan \\ Email: bangunhardika@ukmc.ac.id
}

\begin{abstract}
ABSTRAK
Latar Belakang: Diabetes melitus adalah kelompok gangguan metabolik heterogen yang menyebabkan hiperglikemia, akibat dari ketidakadekuatan produksi insulin, ketidakadekuatan sekresi insulin, atau kombinasi keduannya. Penyakit diabetes melitus membutuhkan perawatan berkelanjutan dan pendidikan pengelolaan diri pasien yang sedang berlangsung dan dukungan untuk mencegah komplikasi akut dan mengurangi risiko komplikasi jangka panjang.

Tujuan: Penelitian untuk mengetahui pengaruh senam kaki diabetes terhadap penurunan kadar gula darah pada pasien diabetes mellitus tipe II

Metode: Penelitian ini menggunakan metode kuantitatif pra eksperimen dengan pendekatan one group pretest-posttest. Populasi dalam penelitian ini adalah pasien yang telah didiagnosa Diabetes Mellitus Tipe II yang ada di Puskesmas Sosial KM.5 Palembang, jumlah sampel yang digunakan sebanyak 30 responden. Pengukuran kadar gula darah dengan menggunakan Glukometer sebelum dan sesudah dilakukan senam kaki diabetes. Data dianalisis dengan menggunakan uji Paired t-test.

Hasil: Hasil penelitian menunjukan nilai rata-rata kadar gula darah sebelum melakukan senam kaki $202.67 \mathrm{mg} / \mathrm{dll}$, setelah senam kaki menurun menjadi $173.07 \mathrm{mg} / \mathrm{dl}$. Hasil analisis menunjukkan adanya perbedaan kadar gula darah yang signifikan pada pasien diabetes mellitus tipe II sebelum dan setelah melakukan senam kaki diabetes $(p<0.01)$

Kesimpulan: Senam kaki diabetes dapat menurunkan kadar gula darah secara signifikan pada pasien dengan diabetes mellitus tipe II.
\end{abstract}

Kata Kunci: Diabetes Melitus Tipe II; Kadar Gula Darah; Senam Kaki Diabetes

\section{PENDAHULUAN}

Era globalisasi terjadi pergeseran dari penyakit menular ke penyakit tidak menular, semakin banyak muncul penyakit degeneratif salah satunya adalah Diabetes Melitus (DM). Diabetes merupakan penyakit kronis dikarenakan sekresi insulin endogen yang tidak efektif. Diabetes diklasifikasikan menjadi diabetes tipe 1 Insulin Dependen Diabetes Mellitus (IDDM) dan tipe II disebut Non-Dependen Insulin Diabetes Mellitus (NDIDM) (Longmore, dkk 2014).

Estimasi terakhir International Diabetes Federation (IDF) tahun 2013, di dunia lebih dari 382 juta orang terkena DM, dan pada tahun 2035 jumlah tersebut diperkirakan akan meningkat menjadi 592 juta orang. Setiap tahun ada 3,2 juta kematian yang disebabkan langsung oleh diabetes. Berarti ada 1 orang per 10 detik atau 6 orang per menit yang meninggal akibat penyakit yang berkaitan dengan DM. Penderita DM mengalami peningkatan secara global. Tahun 2014 diperkirakan 422 juta jiwa menderita DM. Peningkatan angka kejadian dari tahun 1990-2014 sekitar 4,7\%-8,5\% pada populasi dewasa. Tahun 2012 DM adalah penyebab angka kematian tertinggi kurang lebih 12.650 .340 orang atau $0,6 \%$ dari seluruh penduduk di Indonesia yang berusia diatas 15 tahun, pernah didiagnosa menderita Diabetes Melitus (WHO, 2014). Prevalensi penderita Diabetes mellitus terbanyak ada di Jawa Timur yaitu 605.974 orang. 
Sementara di Sumatera Selatan sendiri berdasarkan data Infodatin Kemenkes RI. (2014), penderita DM sebanyak 49.318 orang. berdasarkan studi pendahuluan yang dilakukan peneliti di Puskesmas Sosial KM. 5 Palembang, ditemukan bahwa data pasien DM mengalami peningkatan dari bulain september sampai desember yaitu bulan September 2016 sebanyak 23 orang penderita DM, bulan November 27 Orang penderita DM, dan pada bulan Desember 31 Orang Penderita DM.

Komplikasi penyakit diabetes melitus yang sering dijumpai adalah stroke, jantung, Neuropati (kerusakan syaraf), gagal ginjal, dan kaki diabetik (diabetic foot) yang dapat bermanifestasikan sebagai ulkus, infeksi dan gangren. Ada dua tindakan dalam prinsip dasar pengelolaan diabetic foot yaitu tindakan pencegahan dan tindakan rehabilitasi. Tindakan rehabilitasi meliputi program terpadu yaitu evaluasi tukak, pengendalian kondisi metabolik, debridemen luka, biakan kuman, antibiotika tepat guna, tindakan bedah rehabilitatif dan rehabilitasi medik. Tindakan pencegahan meliputi edukasi perawatan kaki, sepatu diabetes dan senam kaki (Flora, Hikayati, dan Purwanto, 2012).

Upaya dalam mengendalikan gula darah tidak efektif hanya dilakukan dengan pengobatan saja. Hal tersebut dikarenakan penderita yang mengalami diabetes melitus disebabkan oleh kerusakan pankreas dalam memproduksi insulin, dimana insulin ini berfungsi dalam mengendalikan kadar gula darah. Penurunan kadar gula darah ini sebagai salah satu indikasi terjadinya perbaikan diabetes mellitus yang dialami. Oleh karena itu pemberian aktivitas senam kaki merupakan salah satu cara yang efektif dalam mengelola diabetes melitus (Ruben, Rottie, dan Karundeng, 2016).

Senam kaki diabetes melitus merupakan kegiatan atau latihan yang di lakukan oleh penderita diabetes melitus untuk mencegah terjadinya luka dan membantu melancarkan peredaran darah bagian kaki. Senam kaki diabetes dapat membantu memperbaiki sirkulasi darah dan memperkuat otot-otot kecil kaki dan mencegah terjadinya kelainan bentuk kaki. Selain itu dapat meningkatkan kekuatan otot betis, otot paha, dan juga mengatasi keterbatasan pergerakan sendi (Agustianingsih, 2013).

Senam direkomendasikan dilakukan dengan intensitas moderat (60-70 maksimum heart rate), durasi 30-60 menit, dengan frekuensi 3-5 kali per minggu dan tidak lebih dari 2 hari berturut-turut tidak melakukan senam (Ruben, Rottie, dan Karundeng, 2016).

Olahraga akan meningkatkan pemakaian glukosa oleh otot yang aktif, dimana otot mengubah simpanan glukosa menjadi energi sehingga secara langsung dapat menyebabkan penurunan glukosa dalam darah. Selain itu, pada saat berolahraga atau melakukan latihan fisik terjadi pembakaran kalori yang menambah metabolisme tubuh, sehingga selain dapat mengendalikan kadar gula darah juga dapat menurunkan berat badan. Olahraga akan mengurangi jumlah kolesterol LDL, meningkatkan HDL, dan mengurangi trigliserida 4 dalam darah, yang berarti yang berarati mengurangi risiko komplikasi penyakit jantung kardiovaskuler. Dengan demikian olahraga bukan hanya akan 
memberikan perbaikan dalam diabetes melitus, namun juga dapat mengurangi risiko terjadinya komplikasi (Meirani, 2014).

Parichehr, et al (2012) mengatakan senam kaki diabetes dapat mengendalikan perubahan kadar gula darah yaitu pada otot-otot yang bergerak aktif dapat meningkatkan kontraksi sehingga permeabilitas membran sel terhadap peningkatan glukosa, resistensi insulin berkurang dan sensitivitas insulin meningkat. Sehingga sirkulasi dalam darah meningkat dan terjadi penurunan kadar gula darah pada pasien dengan diabetes (Rizaniansyah \& Farianingsih, 2015). Tujuan dalam penelitian ini adalah untuk mengetahui pengaruh senam kaki terhadap penurunan gula darah pada penderita DM tipe II.

\section{METODE}

Penelitian ini termasuk dalam area masalah Keperawatan Komunitas merupakan penelitian observasional analitik. Penelitian ini menggunakan metode kuantitatif pra eksperimen dengan pendekatan one group pretest-posttest (Sunyoto, Danang, dan Setiawan, 2013). Populasi dalam penelitian ini adalah pasien yang telah didiagnosa Diabetes Mellitus Tipe II yang ada di Puskesmas Sosial KM.5 Palembang. Sampel pada penelitian ini menggunakan Total Sampling (Sugiyono. 2013). yakni semua populasi dijadikan responden. Data pasien diabetes mellitus tipe II yang berobat di Puskesmas Sosial pada bulan Desember 2016 berjumlah 30 pasien (Puskesmas Sosial, 2017). Sehingga seluruh pasien yang berobat ke puskesmas sosial diambil semua sebagai responden yang berjumlah 30 responden.
Kriteria inklusi yang digunakan pada penelitian ini adalah Pasien yang menderita diabetes mellitus tipe II, pasien yang bisa berdiri dan duduk, bersedia menjadi responden, pasien yang mengikuti senam dari awal hingga akhir

Instrumen yang digunakan dalam peneliti adalah alat ukur gula darah (Glukometer) (Damayanti, 2015), dan diperkuat oleh lembar hasil Observasi. Pengolahan data pada penelitian ini menggunakan Uji Paired sample T-test (Saryono, 2013). dengan tingkat kemaknaan $(\rho \leq 0,05)$

\section{HASIL}

Berdasarkan karakteristik responden pada penelitian ini diketahui sebanyak $16,7 \%$ (5 responden) berjenis kelamin laki-laki, dan sebanyak $83,3 \%$ (25 responden) dengan jenis kelamin perempuan. Sedangkan karakteristik responden menurut usia yang mengalami diabetes tipe II diantara Usia 40-49 tahun sebanyak 10 responden dengan persentase $33.3 \%$, usia 50-59 tahun sebanyak 14 responden dengan persentase $46.7 \%$, usia 60-70 sebanyak 6 responden dengan persentase $20.0 \%$. (Tabel 1 )

Rata-rata hasil pengukuran gula darah pada 30 responden sebelum dilakukan senam kaki diabetes adalah $202.67 \mathrm{mg} / \mathrm{dl}$, dengan nilai terendah $187.65 \mathrm{mg} / \mathrm{dl}$, dan nilai tertinggi $217.68 \mathrm{mg} / \mathrm{dl}$. Sedangkan hasil pengukuran Gula darah pada 30 responden sesudah dilakukan senam kaki diabetes adalah $173.07 \mathrm{mg} / \mathrm{dl}$, dengan nilai terendah $158.90 \mathrm{mg} / \mathrm{dl}$, dan nilai tertinggi $187.23 \mathrm{mg} / \mathrm{dl}$ (tabel 2).

Hasil pada uji paried sampel t-test 

Diabetes

didapatkan nilai $\mathrm{t}=8,62 ; p$ value $=0,001(p$ $<0,05)$. Hal ini menunjukkan bahwa ada pengaruh yang signifikan senam kaki diabetik terhadap penurunan kadar gula darah pada pasien diabetes mellitus tipe II. (tabel 2).

Tabel 1. Karakteristik Responden $(n=30)$

\begin{tabular}{lcc}
\hline Karakteristik & Frekuensi & Persentase \\
\hline Usia (Tahun) & & \\
$40-49$ & 10 & $33.3 \%$ \\
$50-59$ & 14 & $46.7 \%$ \\
$60-70$ & 6 & $20.0 \%$ \\
Jenis kelamin & 5 & $16.7 \%$ \\
Laki-laki & $5 \%$ & $83.3 \%$ \\
\hline Perempuan & 25 & \\
\hline
\end{tabular}

Tabel 2. Perbedaan Penurunan Kadar Gula Darah pada Pasien Diabetes Mellitus Tipe II Sebelum dan Setelah Senam Kaki Diabetes $(n=30)$

\begin{tabular}{lcccc}
\hline Variabel & Mean \pm SD & Mean dif & t & p-value \\
\hline $\begin{array}{c}\text { Kadar Gula Darah } \\
\text { Sebelum Senam Kaki Diabetes }\end{array}$ & $202.67 \pm 40.209$ & 29.6 & 8.62 & 0.001 \\
Setelah Senam Kaki diabetes & $173.07 \pm 37.935$ & & &
\end{tabular}

Paire t-test

\section{PEMBAHASAN}

Rata-rata hasil pengukuran kadar gula darah pada penderita diabetes dari 30 responden terdapat penurunan kadar gula darah sebesar 29,6 mg/dl dengan rata-rata sebelum dilakukan senam kaki 202,67 mg/dl, dan rata-rata sesudah dilakukan senam kaki adalah $173,07 \mathrm{mg} / \mathrm{dll}$, dengan nilai $p$ value pada uji paried sampel $t$-test adalah 0,001 ( $p<$ $0,05)$, maka dapat disimpulkan bahwa ada pengaruh senam kaki diabetes terhadap penurunan kadar gula darah pada pasien DM tipe II.

Hasil penelitian ini sejalan dengan penelitian Rusli dan Farianingsih (2015) bahwa dari 20 responden yang dilakukan penelitian didapatkan pada hari pertama sebelum di intervensi sebagian besar 70\% (14 responden) kadar gula darahnya pada interval 240-249, Pada hari kedua sebelum di intervensi sebagian besar responden $70 \%$ (14 responden) kadar gula darahnya pada interval 230-239 Dan hari ketiga sebelum intervensi sebagian besar responden 60\% (12 responden) kadar gula darahnya pada interval 220-229. Penelitian ini juga menunjukan bahwa ada pengaruh kuat senam kaki diabetes terhadap penurunan kadar gula darah pada pasien diabetes melitus tipe II. Senam kaki diabetes sangat dibutuhkan dalam pengelolaan diabetes melitus, latihan jasmani secara teratur dapat menurunkan kadar gula darah.

Menurut Aini dan Aridiana (2016), gangguan utama justru terjadi pada volume reseptor (penerima) hormon insulin, yakni sel-sel darah. Dalam kondisi ini produktivitas hormone insulin bekerja dengan baik, namun tidak terdukung oleh kuantitas volume reseptor yang cukup pada sel darah, keadaan ini dikenal dengan resistensi insulin. Gangguan sekresi insulin terjadi karena sel 
beta pankreas tidak mampu mensekresikan insulin sesuai dengan kebutuhan. Dengan demikian insulin menjadi menjadi tidak efektif untuk menstimulasi pengambilan glukosa oleh jaringan.

Terjadi penurunan kadar gula darah antara sebelum dan sesudah diberikan perlakuan senam kaki diabetes, hal ini disebabkan adanya pengaruh pemberian senam kaki diabetes. Hasil penelitian ini juga didukung dengan penelitian Santosa dan Rusmono (2016) yang mengemukakan bahwa senam kaki pada pasien diabetes melitus dapat menurunkan kadar gula darah sewaktu dari intervensi I sampai intervensi ke IV dengan nilai $\mathrm{p}<0,005$, dalam penelitiannya dikemukakan bahwa dengan senam kaki diabetes dapat menurunkan kadar gula darah sewaktu dikarenakan efek dari senam kaki tersebut dapat meningkatkan sensitifitas sel terhadap insuliln sehingga gula darah akan masuk ke sel untuk dilakukan metabolisme, selain itu penelitian ini juga memberikan gambaran bahwa seiring dengan dilkukannya senam kaki kadar gula darah pasien juga semakin stabil dengan tren penurunan kadar gula darah sejak tretment I sampai treatment ke IV, sehingga dalam penelitiannya disimpulakan bahwa senam kaki harus dilakukan penderita diabetes melitus setiap hari agar gula darahnya selalu stabil.

Hasil penelitian Ini juga sejalan dengan penelitian yang dilakukan oleh Ruben, Rottie, Karundeng, (2016), menunjukan bahwa adanya pengaruh bermakna Antara sebelum dan sesudah dilakukan senam kaki diabetes. Selain itu Ruben, Rottie, dan Karundeng 2016 dalam penelitiannya mengemukakan bahwa dalam menurunkan kadar gula darah pada pasien DM tipe II harus memperhatikan faktor-faktor yang mempengaruhi seperti olah raga setiap hari, Selain itu penderita DM juga dianjurkan setiap harinya untuk melakukan latihan jasmani. Salah satu contoh latihan jasmani atau olahraga yang dianjurkan salah satunya adalah senam kaki diabetes. Senam direkomendasikan dilakukan dengan intensitas moderat (60-70 maksimum heart rate), durasi 30-60 menit, dengan frekuensi 3-5 kali per minggu dan tidak lebih dari 2 hari berturut-turut tidak melakukan senam.

Adapun tujuan yang diperoleh setelah melakukan senam kaki ini adalah memperbaiki sirkulasi darah pada kaki pasien diabetes, sehingga nutrisi lancar kejaringan tersebut. Senam kaki diabetes dapat membantu sirkulasi darah dan memperkuat otot-otot kecil kaki dan mencegah terjadinya kelainan bentuk kaki, mengatasi keterbatasan jumlah insulin pada penderita DM mengakibatkan kadar gula dalam darah meningkat hal ini menyebabkan rusaknya pembuluh darah, saraf dan struktur.

Senam kaki diabetes juga digunakan sebagai latihan kaki yang dipercaya untuk mengelola pasien yang mengalami DM, dengan latihan kaki tersebut maka akan merasa nyaman, mengurangi nyeri, mengurangi kerusakan saraf dan mengontrol gula darah serta meningkatkan sirkulasi darah pada kaki (Flora, Hikayati, Purwanto, 2012).

Hasil penelitian ini secara umum memberikan gambaran bahwa pemberian terapi senam kaki diabetes dapat menurunkan kadar gula darah pada penderita diabetes mellitus serta memberikan pengaruh. 

Diabetes

Secara khusus, pemberian terapi senam kaki diabetes dapat diterapkan dalam menurunkan kadar gula darah pada penderita diabetes mellitus. Sejalan dengan dilakukannya senam kaki diabetes, otot-otot serta syaraf dalam tubuh dapat terkontrol sehingga memberikan rasa nyaman, mengurang nyeri serta dapat meningkatakan sirkukasi darah pada kaki pasien.

Penderita diabetes mellitus yang mendapatkan terapi senam kaki diabetes yang terarah dan teratur akan lebih cepat menagalami penurunan kadar gula darah. Pada dasarnya pemberian senam kaki diabetes dapat memberikan bimbingan pada penderita diabetes untuk melakukan senam kaki diabetes di rumah sendiri, sehingga setiap harinya penderita diabetes mellitus akan secara tidak langsung dapat mengurangi kadar gula darah atau dapat mencegah komplikasi yang dapat terjadi pada penderita diabetes mellitus selanjutnya.

Senam kaki diabetes dapat mempengaruhi penurunan kadar gula yakni terjadi akibat darah pada otot-otot yang bergerak aktif dapat meningkatkan kontraksi sehingga permeabilitas membran sel terhadap peningkatan glukosa, resistensi insulin berkurang dan sensitivitas insulin meningkat. Sehingga sirkulasi dalam darah meningkat dan terjadi penurunan kadar gula darah pada pasien dengan diabetes mellitus. selain itu penurunan kadar gula darah juga didukung oleh kesadaran responden yang meningkat dalam hal memperhatikan pola makan agar kadar gula darah dalam tubuh tidak meningkat lagi.

\section{KESIMPULAN DAN SARAN}

Berdasarkan hasil penelitian yang telah dilakukan dapat disimpulkan senam kaki diabetes secara signifikan dapat menurunkan kadar gula darah pada pasien diabetes mellitus tipe II $(p<0.01)$. Hendaknya pada pasien diabetes melakukan senam kaki diabetes secara rutin untuk mengendalikan kadar gula darahnya.

\section{DAFTAR PUSTAKA}

Aini dan Ardiana. (2016). Asuhan Keperawatan pada Sistem Endokrin dengan Pendekatan NANDA, NIC, NOC. Jakarta: Salemba Medika

Damayanti, Santi. (2015). Diabetes Mellitus dan Penatalaksanaan Keperawatan. Jakarta: Medikal Book

Flora. Rostika, Hikayati \& Purwanto. Sigit. (2012). Pelatihan Senam Kaki Pada Penderita Diabetes Mellitus Dalam Upaya Pencegahan Komplikasi Diabetes Pada Kaki (Diabetes Foot). Jurnal Pengabdian Sriwijaya Fakultas IImu Kesehatan UNSRI. 1(1), 7-15. https://ejournal.unsri.ac.id/index.php/j psriwijaya/article/view/1543/606

Infodatin Kemenkes RI. (2014). Pusat Data dan Informasi Kementrian Kesehatan Republik Indonesia: Situasi dan Analisis Diabetes Mellitus. Jakarta: Media Publis Kemenkes RI dikutip dari www.depkes.go.id tanggal 03 Februari 2017

Longmore. Murray, dkk. (2014). Buku Saku Oxfort Kedokteran Klinis Edisi 8. Jakarta: EGC

Parichehr, K., Mohamad, T.N., Soheilikhah, Marsyam, R. (2012). Evaluation of patients education on foot self-care status in diabetic patients. Iranian Red Crescent Medical Jurnal, 14(12) :829-832. https://www.ncbi.nlm.nih.gov/pmc/arti cles/PMC3587876/

Puskesmas Sosial. (2017). Data Pasien Diabetes Mellitus tahun 2016 di Puskesmas Sosial Kecamatan Sukarami Palembang.

Ruben. Graceistin, Rottie. Julia Villy \& Karundeng. Y. Michael. (2016). Pengaruh Senam Kaki 
Diabetes Terhadap Perubahan

Kadar Gula Darah Pada

Pasien Diabetes Melitus Tipe

2 Di Wilayah Kerja Puskesmas

Enemawira.

https://ejournal.unsrat.ac.id/index.php

/jkp/article/view/11897

Rizaniansyah R. Gusti \& Farianingsih Septi.

(2015). Senam Kaki Diabetes

Menurunkan Kadar Gula Darah

Pasien Diabetes Mellitus Tipe 2

(Diabetic Feet Gymnastic to

Decrease Blood Sugar

Levels Diabetes Mellitus type 2

Patients). Jurnal Of Ners Community.

http://journal.unigres.ac.id/index.php/

JNC/article/view/51

Santosa A, Rusmono W. (2016). Senam kaki untuk mengendalikan kadar gula darah dan menurunkan tekanan brachial pada pasien diabetes melitus. Jurnal IImiah IImu-IImu Kesehatan Universitas Muhammadiyah Purwokerto. 14(2) 24-34

http://jurnalnasional.ump.ac.id/index. php/medisains/article/view/1653

Sugiyono. (2013). Metode Penelitian Kuantitatif dan Kualitatifdan $R$ \& $D$. Edisi cetakan ke 18. Bandung: Alfabeta

Sunyoto, Danang \& Setiawan, Ari. (2013). Buku Ajar Statistik Kesehatan, Parametrik, Non Parametrik, Validitas dan Reliabilitas dan Analisis data. Yogyakarta: Nuha Medika

WHO. 2014. World Health Statistic 2014. Geneva: World Health Organization. Tersedia di: http://apps.who.int/iris/bitstream/1066 5/112738/1/9789240692671_eng. 